\title{
Surgical site infections following instrumented stabilization of the spine
}

\author{
This article was published in the following Dove Press journal: \\ Therapeutics and Clinical Risk Management \\ 20 September 2017 \\ Number of times this article has been viewed
}

\author{
Ulrike Dapunt ${ }^{1}$ \\ Caroline Bürkle' \\ Frank Günther ${ }^{2}$ \\ Wojciech Pepke' \\ Stefan Hemmer' \\ Michael Akbar' \\ 'Clinic for Orthopedics and Trauma \\ Surgery, Center for Orthopedics, \\ Trauma Surgery and Spinal Cord \\ Injury, Heidelberg University \\ Hospital, ${ }^{2}$ Department for Infectious \\ Diseases, Medical Microbiology and \\ Hygiene, Heidelberg University, \\ Heidelberg, Germany
}

\begin{abstract}
Background: Implant-associated infections are still a feared complication in the field of orthopedics. Bacteria attach to the implant surface and form so-called biofilm colonies that are often difficult to diagnose and treat. Since the majority of studies focus on prosthetic joint infections (PJIs) of the hip and knee, current treatment options (eg, antibiotic prophylaxis) of implant-associated infections have mostly been adapted according to these results.

Objective: The aim of this study was to evaluate patients with surgical site infections following instrumented stabilization of the spine with regard to detected bacteria species and the course of the disease.
\end{abstract}

Patients and methods: We performed a retrospective single-center analysis of implantassociated infections of the spine from 2010 to 2014. A total of 138 patients were included in the study. The following parameters were evaluated: C-reactive protein serum concentration, microbiological evaluation of tissue samples, the time course of the disease, indication for instrumented stabilization of the spine, localization of the infection, and the number of revision surgeries required until cessation of symptoms.

Results: Coagulase-negative Staphylococcus spp. were most commonly detected ( $\mathrm{n}=69,50 \%)$, followed by fecal bacteria ( $n=46,33.3 \%$ ). In $23.2 \%$ of cases, no bacteria were detected despite clinical suspicion of an infection. Most patients suffered from degenerative spine disorders (44.9\%), followed by spinal fractures $(23.9 \%)$, non-degenerative scoliosis $(20.3 \%)$, and spinal tumors (10.1\%). Surgical site infections occurred predominantly within 3 months $(64.5 \%)$, late infections after 2 years were rare (4.3\%), in particular when compared with PJIs. Most cases were successfully treated after 1 revision surgery (60.9\%), but there were significant differences between bacteria species. Fecal bacteria were more difficult to treat and often required more than 1 revision surgery.

Conclusion: In summary, we were able to demonstrate significant differences between spinal implant-associated infections and PJIs. These aspects should be considered early on in the treatment of surgical site infections following instrumented stabilization of the spine.

Keywords: surgical site infection, biofilm infection, instrumentation of the spine, coagulasenegative Staphylococci

\section{Introduction}

Surgical site infections still pose a major complication in the field of orthopedics. ${ }^{1,2}$ In particular, infections associated with an implant are especially difficult to treat since bacteria attach to the implant surface and form so-called biofilm colonies., ${ }^{3,4}$ In this form, bacteria are better protected from the immune system and are more resistant to antibiotics and biocides. ${ }^{5,6}$ Therefore, biofilm formation is currently thought to be the preferred lifestyle of bacteria and considered the most common cause for persistent infections. ${ }^{7}$ Gram-positive bacteria, among them mostly species belonging 
to the Staphylococcus genus, are frequently detected in orthopedic implant-associated infections. ${ }^{8,9}$ Staphylococcus aureus has been traditionally described as the most common causative agent, however, recently also coagulase-negative Staphylococci have been acknowledged as predominant in early (within 3 months after surgery), delayed (3 to 24 months after surgery), and late ( $>2$ years after surgery) prosthetic joint infections (PJIs). ${ }^{10,11}$ Furthermore, an alarming increase in infections caused by Enterococcus spp. over the last 30 years has been reported. ${ }^{12-14}$

There is an abundance of literature available on the epidemiology and treatment of PJIs of the hip and knee, and therapeutic guidelines concerning empiric antibiotic treatment or surgical intervention in implant-associated infections are frequently derived from these data. ${ }^{11,12,15-17}$

However, surgical site infections following instrumented fixation of the spine pose another major problem to the orthopedic surgeon, since removal of the implant and hence, removal of the biofilm surface is usually not recommended due to the risk of loss of correction and stability of the spine ${ }^{18}$ (reviewed in Ref. 19 and 20). Therefore, early recognition of symptoms, followed by aggressive debridement and irrigation, and thoughtful empiric antibiotic treatment seem to be highly important. ${ }^{21-23}$

The aim of this study was to evaluate characteristics of implant-associated infections of the spine, in particular with regard to bacteria species detected, as well as the course of the infection, and compare these data to PJIs.

\section{Patients and methods}

\section{Patients}

We performed a retrospective single-center analysis of patients treated surgically due to implant-associated infection of the spine at a single, specialized center (Clinic for Orthopedics and Trauma Surgery, Heidelberg University Hospital). From January 2010 until December 2014, a total of 138 patients who previously received anterior and/or posterior instrumented stabilization of the spine were included in the study. The project was approved by the local ethics committee of the Faculty of Medicine at Heidelberg University (S-032/2017). Patients' consent to review their medical records was not required by the local ethics committee. Patient's name and any confidential information were bound to medical confidentiality and the regulations of the German Federal Data Protection Act (BDSG). Data will only be disclosed to third parties if they are pseudonymized to ensure patient data confidentiality.
Diagnosis of an infection was determined according to clinical signs (erythema, swelling, hyperthermia, pain, pus intraoperative, fistula, protracted wound healing, and persistent wound drainage), positive laboratory diagnostics (elevated C-reactive protein [CRP] serum concentration and white blood cell count) and detection of bacteria by culture of tissue samples (1 to 3 samples). White blood cell count did not show significant differences; therefore, CRP serum concentration only was evaluated in further depth.

The following parameters were examined: patients' age and gender, CRP serum concentration (reference value $<5 \mathrm{mg} / \mathrm{L}$ ), bacteria detected in tissue samples, time elapsed since index surgery of the spine with instrumented stabilization, time elapsed since last surgical revision, primary indication to perform surgical stabilization other than infection (spinal tumor, degenerative spine disorders, spinal fracture, and non-degenerative scoliosis), localization of the infection (cervical, upper thoracic, lower thoracic, and lumbar spine), long-segment spinal fixation (defined as $>6$ levels stabilized), and the number of surgical interventions required until cessation of symptoms of an infection.

Differences between groups were calculated using chisquare test and Mann-Whitney test using Origin 9.0 software (OriginLab, Northampton, MA, USA) and Microsoft Excel. Significance level was determined as $p<0.05$.

\section{Methods}

Tissue samples were processed according to the following protocol: after arrival at the Department for Infectious Diseases, Medical Microbiology and Hygiene of Heidelberg University, the tissue was ground using a sterile porcelain mortar, followed by the addition of $1 \mathrm{~mL}$ of $0.9 \% \mathrm{NaCl}$. This suspension was inoculated onto Columbia 5\% sheep blood agar (BD life sciences, Heidelberg, Germany), chocolate agar, MacConkey agar, SCS agar, Schaedler Neo Vanco $+5 \%$ sheep blood (SNVS) agar (all BioMérieux, Marcy, France), and thioglycolate broth (BD life sciences), and then Gram staining was performed. Samples were incubated under aerobic or anaerobic conditions, as appropriate, for $48 \mathrm{~h}$ (aerobic microorganisms) or $72 \mathrm{~h}$ (anaerobic microorganisms) at $36^{\circ} \mathrm{C}$. If growth on plates was detected, identification of microorganisms was performed by matrix-assisted laser desorption ionization-time-of-flight mass spectrometry (Bruker Daltonics, Bremen, Germany) as described elsewhere. ${ }^{24}$ Susceptibility testing was performed using VITEK2 (Biomérieux, Nürtingen, Germany) or MIC test strips (Liofilchem, Piane Romano, Italy), respectively, and the 
results were interpreted according to the European Committee on Antimicrobial Susceptibility Testing clinical breakpoints.

\section{Results \\ Clinical data}

Of the 138 patients included in the study, 49 were female and 89 were male. Average age was 62.5 years. CRP serum concentration was elevated in $86.2 \%$ of patients, and bacteria were detected in $76.8 \%$ of tissue samples. The majority of infections occurred within 3 months of the index surgery $(64.5 \%)$, whereas late infections ( $>2$ years) were only detected in $23(16.7 \%)$ patients. However, 17 of the latter patients had previously undergone revision surgery before occurrence of infection (14 patients within 3 months and 3 patients within 3 months-2 years). Therefore, when the time elapsed since the last surgical intervention was evaluated, merely 6 cases $(4.3 \%)$ showed late infection.

Concerning the primary indication for stabilization of the spine, most patients suffered from degenerative spine disorders (44.9\%), followed by spinal fractures (23.9\%), nondegenerative scoliosis (20.3\%), and spinal tumor (10.1\%). Of note, 19 of the 28 scoliosis patients requiring revision surgery due to an infection suffered from an underlying neurological disorder.

In most cases, the lumbar spine was affected and the number of infections gradually decreased toward the cervical spine. Long-segment spinal fixation was performed in $47.8 \%$ of patients and in the majority of cases, 1 revision surgery $(60.9 \%)$ was sufficient for cessation of symptoms of an infection.

The summary of clinical data of patients included in this study is listed in Table 1.

\section{Bacteria species}

A total of 144 bacteria species were detected by microbiological evaluation of tissue samples (Table 2). In 23.2\%, tissue samples were culture-negative despite clinical signs of an infection. Polymicrobial infection was detected in 35 cases (in most cases, these were a combination of coagulase-negative Staphylococci and fecal bacteria, followed by a combination of various fecal bacteria detected in tissue samples).

The most commonly detected bacteria species were by far coagulase-negative Staphylococci and fecal bacteria (Enterococcus spp., Escherichia coli, Klebsiella spp., Enterobacter spp., Proteus spp., Citrobacter spp.) (Figure 1). Therefore, these 2 groups were investigated in further depth.
Table I Clinical data of patients included in the study

\begin{tabular}{|c|c|}
\hline \multicolumn{2}{|l|}{ Patients with spinal implant infection } \\
\hline Number of patients included in the study & 138 \\
\hline \multirow[t]{2}{*}{ Age (years) } & Median 62.5; range \\
\hline & 7-87; IQR 23.75 \\
\hline Gender n (\%) & $\begin{array}{l}\text { Female } 49(35.5) \\
\text { male } 89(64.5 \%)\end{array}$ \\
\hline \multicolumn{2}{|l|}{$\begin{array}{l}\text { Elevated CRP serum concentration } \\
\text { (reference value }>5 \mathrm{mg} / \mathrm{L}) \mathrm{n}(\%)\end{array}$} \\
\hline Bacteria detected in tissue samples $\mathrm{n}(\%)$ & $106(76.8)$ \\
\hline \multicolumn{2}{|c|}{ Time elapsed since index surgery with instrumented } \\
\hline \multicolumn{2}{|l|}{ fixation $\mathrm{n}(\%)$} \\
\hline$<3$ months & $89(64.5)$ \\
\hline 3 months to 2 years $n(\%)$ & $26(18.8)$ \\
\hline$>2$ years $n(\%)$ & $23(16.7)$ \\
\hline \multicolumn{2}{|l|}{ Time elapsed since last surgical revision } \\
\hline$<3$ months $\mathrm{n}(\%)$ & $107(77.5)$ \\
\hline 3 months to 2 years $n(\%)$ & $25(18.2)$ \\
\hline$>2$ years $\mathrm{n}(\%)$ & $6(4.3)$ \\
\hline \multicolumn{2}{|l|}{ Indication for index surgery } \\
\hline Tumor n (\%) & $14(10.1)$ \\
\hline Degenerative disorder $\mathrm{n}(\%)$ & $62(44.9)$ \\
\hline Fracture $\mathrm{n}(\%)$ & $33(23.9)$ \\
\hline Scoliosis n (\%) & $28(20.3)$ \\
\hline Unknown n (\%) & $\mathrm{I}(0.7)$ \\
\hline \multicolumn{2}{|l|}{ Localization of infection } \\
\hline Cervical n (\%) & $24(17.4)$ \\
\hline Upper thoracic n (\%) & $48(34.8)$ \\
\hline Lower thoracic $n(\%)$ & $65(47.1)$ \\
\hline Lumbar n (\%) & 99 (7I.7) \\
\hline \multirow[t]{3}{*}{ Number of stabilized segments } & Median 6 \\
\hline & Range 2-19 \\
\hline & IQR 5.75 \\
\hline Long-segment fixation (>6 levels) n (\%) & $66(47.8)$ \\
\hline \multicolumn{2}{|c|}{$\begin{array}{l}\text { Number of surgical revisions required until cessation of } \\
\text { symptoms of infection } n(\%)\end{array}$} \\
\hline i & $84(60.9)$ \\
\hline 2 & $24(17.4)$ \\
\hline 3 & $12(8.7)$ \\
\hline$>3$ & $18(13.0)$ \\
\hline
\end{tabular}

Notes: Concerning localization of infection; the numbers were calculated proportional to the number of patients $(n=138)$. In many cases, since more than one spinal localization was affected, the total sum of the percentages displayed cannot amount to $100 \%$.

Abbreviations: CRP, C-reactive protein; IQR, interquartile range.

Surprisingly, S. aureus and Streptococcus spp. were merely detected in 7 cases.

When CRP serum concentrations of the 3 groups (no bacteria, coagulase-negative bacteria, and fecal bacteria) were compared, there were significantly higher concentrations detected in infections with fecal bacteria (Figure 2) indicating a more pronounced systemic inflammatory response in these cases.

Concerning the time elapsed since the index surgery, no significant differences could be detected between the 
Table 2 Bacteria species detected in tissue samples

\begin{tabular}{ll}
\hline Bacteria species & $\mathbf{n}$ \\
\hline Staphylococcus epidermidis & 43 \\
Other coagulase-negative Staphylococci (S. capitis, S. haemolyticus, & 26 \\
S. lugdunensis, S. hominis, S. warneri) & \\
S. aureus & 5 \\
Enterococcus spp. & 20 \\
Escherichia coli & 8 \\
Klebsiella spp. & 6 \\
Enterobacter spp. & 7 \\
Proteus spp. & 4 \\
Citrobacter spp. & 1 \\
Bacteroides spp. & 2 \\
Corynebacterium spp. & 8 \\
Pseudomonas spp. & 4 \\
Streptococcus spp. & 2 \\
3MRGN & 2 \\
Bacillus spp. & 2 \\
Candida spp. & 4 \\
\hline
\end{tabular}

3 groups (Table 3). Similarly, localization of infection did not differ significantly between the groups (data not shown).

There was a significant difference in revisions required until cessation of symptoms. Fewer infections caused by fecal bacteria were treated successfully after 1 revision (Table 4).

\section{Comparison with PJI of the hip and knee}

Recently, we published an evaluation of patients $(n=209)$ treated for PJI of the hip and knee. ${ }^{14}$ Bacteria species detected in PJI differed from surgical site infections of the spine. There were far more infections caused by $S$. aureus and Streptococcus spp. in PJI and less caused by fecal bacteria (Figures 1 and 3). Coagulase-negative Staphylococci were the most commonly detected causative agents in both PJI and spinal infections, respectively.

We were also interested in comparing the time course since the index surgery and the last surgical revision in

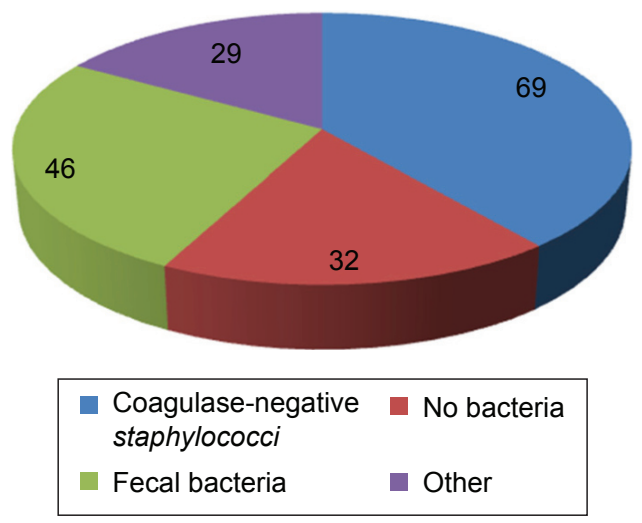

Figure I Numbers of coagulase-negative Staphylococci, fecal bacteria, other bacteria, and no bacteria detected in tissue samples are depicted.

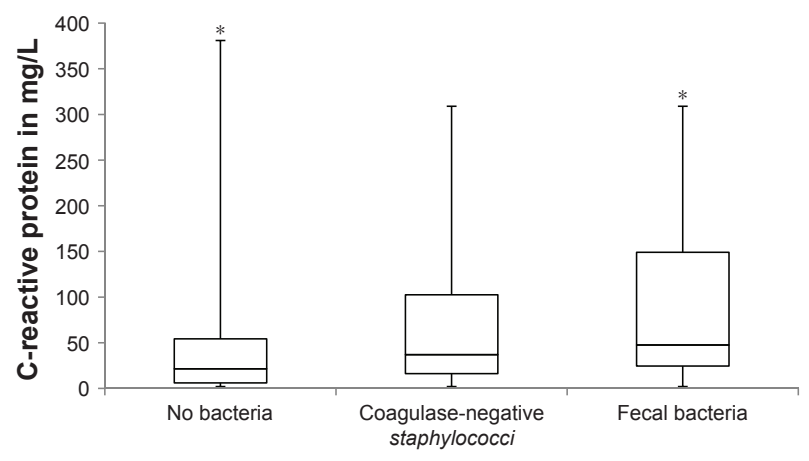

Figure 2 C-reactive protein serum concentration of patients with no bacteria detected in tissue samples and the two most frequently detected bacteria species. Notes: Differences between groups were calculated using Mann-Whitney test. *significantly less compared to fecal bacteria $(p=0.007)$. Significance level was determined as $p<0.05$.

PJI and spinal infections. The time elapsed since the index surgery in PJI (median value in months) was 48 (range 1-408, interquartile range [IQR] 105.75) and in spinal surgery (median value in days) 31 (range 3-8,760, IQR 302.5).

When we compared the time course since the last surgical intervention, there was a striking difference between PJI and spinal implant infection. Spinal infections predominantly occurred within the first 3 months since the last surgical intervention, whereas late infections after 2 years were significantly less compared with PJI (Table 5).

\section{Discussion}

Surgical site infection following instrumented fixation of the spine is a feared complication. Infection rates vary and have been reported to range between $0.7 \%$ and $12 \%$ in medical literature depending on the complexity of surgery and patient risk factors. ${ }^{25,26}$ Usually, revision surgery is required along with a prolonged antibiotic treatment that puts patients at high risk of associated complications and exerts considerable psychological stress. Furthermore, treatment of infections results in high socioeconomic costs. ${ }^{1,19}$ When implant-associated infections occur on the upper or lower extremities, surgical intervention consists of aggressive debridement and irrigation, followed by implant removal, if necessary.

Table 3 Time elapsed since primary implantation of foreign material until revision surgery due to infection

\begin{tabular}{llll}
\hline & $\begin{array}{l}\text { No bacteria } \\
\text { (\%) }\end{array}$ & $\begin{array}{l}\text { Coagulase-negative } \\
\text { Staphylococci (\%) }\end{array}$ & $\begin{array}{l}\text { Fecal } \\
\text { bacteria (\%) }\end{array}$ \\
\hline$<3$ months & 68.2 & 65.6 & 61.1 \\
3 months & 16.7 & 18.8 & 16.6 \\
to 2 years & & 15.6 & 22.2 \\
$>2$ years & 15.2 & 1 & \\
\hline
\end{tabular}


Table 4 Number of revision surgeries required until cessation of symptoms

\begin{tabular}{llll}
\hline & $\begin{array}{l}\text { No bacteria } \\
(\%)\end{array}$ & $\begin{array}{l}\text { Coagulase-negative } \\
\text { Staphylococci (\%) }\end{array}$ & $\begin{array}{l}\text { Fecal bacteria } \\
(\%)\end{array}$ \\
\hline 1 & 63.6 & 78.1 & $\begin{array}{l}38.9 \% *(p=0.022, \\
p=0.0014)\end{array}$ \\
2 & 18.2 & 12.5 & 30.6 \\
3 & 9.1 & 3.1 & 11.1 \\
$>3$ & 9.1 & 6.3 & 19.4 \\
\hline
\end{tabular}

Notes: *Significantly less compared to the other two groups. The difference was calculated using chi-square test. Significance level was determined as $p<0.05$.

In spinal surgery, however, implant removal is mostly not a feasible option due to the risk of spinal instability that might result in neurological injury. Additionally, patients who do not have mechanical stability are at higher risk for pseudarthrosis and loss of correction. ${ }^{18}$ Therefore, in spinal infections, early recognition of symptoms, aggressive surgical debridement, and irrigation, along with empiric antibiotic treatment are essential to avoid implant removal. ${ }^{21}$

The aim of this study was to retrospectively evaluate patients treated for surgical site infections following instrumented fixation of the spine at a single institution over the course of 5 years.

We found that coagulase-negative Staphylococci were by far the most frequently detected causative agents of surgical site infections of the spine, followed by fecal bacteria. This is in contrast to the majority of data found in literature, according to which $S$. aureus was most commonly detected. ${ }^{21,22,26,27}$ According to our data, merely 5 cases (3.6\%) were caused by S. aureus, which therefore support the notion that coagulasenegative Staphylococci now seem to be predominant in implant-associated infections.

The high number of fecal bacteria in spinal infections is in line with data in literature and points toward a genitourinary

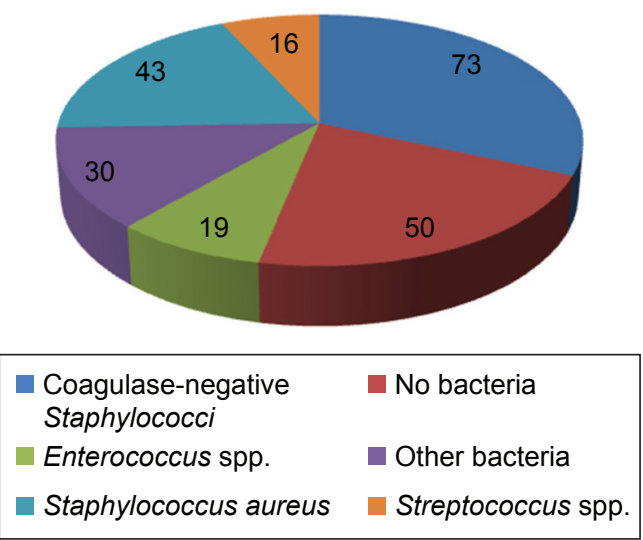

Figure 3 Numbers of the most commonly detected bacteria species and culturenegative cases of patients suffering from prosthetic joint infections. Data from Dapunt et al. ${ }^{14}$
Table 5 Number of patients requiring revision surgery due to an infection after $<3$ months, 3 months to 2 years or $>2$ years since last surgical intervention. Duration of spinal implant infections and prosthetic joint infections are compared

\begin{tabular}{lll}
\hline & $\begin{array}{l}\text { Spinal implant } \\
\text { infection (\%) }\end{array}$ & $\begin{array}{l}\text { Prosthetic joint } \\
\text { infection }(\%)\end{array}$ \\
\hline$<3$ months & 77.5 & $28.5 *(p<0.000 \mathrm{I})$ \\
3 months to 2 years & 18.2 & $36.8 * *(p=0.004 \mathrm{I})$ \\
$>2$ years & 4.3 & $34.7 * *(p<0.000 \mathrm{I})$ \\
\hline
\end{tabular}

Notes: *Significantly less; **significantly more compared to spinal implant infection. The difference was calculated using chi-square test. Significance level was determined as $p<0.05$.

or fecal wound contamination..$^{21,22,27}$ One might therefore expect for these infections to occur mainly at the lumbar spine or lower thoracic spine. However, when we compared the localization of the infections, overall, the lumbar spine was indeed most commonly affected, but there was no significant difference between bacteria species, suggesting also a hematogenous spread of fecal bacteria. A high risk for infections of the spine by Gram-negative bacteria via hematogenous spread has been previously described for trauma cases. ${ }^{28}$

In our study, there was a high number of culturenegative cases (23.2\%) despite clinical suspicion of an underlying infection. This could be due to the fact that these cases were falsely assessed as an infection; however, these numbers are supported by data found in medical literature and we found a similar amount of culture negative cases also in PJIs..$^{14,22}$

Mok et al demonstrated that postoperative kinetics of CRP serum concentration is sensitive for diagnosis of spinal infections. ${ }^{29}$ They observed a postoperative peak in $78 \%$ of patients. In our study, $86.2 \%$ of patients showed elevated CRP serum concentrations. Of note, infections caused by fecal bacteria showed the highest CRP serum concentration when compared with coagulase-negative Staphylococci and culture-negative cases.

We were also interested in evaluating the time course since the index surgery. The majority of infections occurred within 3 months, delayed or late infections were rare. Coagulase-negative Staphylococci, in particular have been described to be associated with delayed, low-grade infections, whereas fecal bacteria such as Enterococcus spp. have been shown to cause early symptoms. ${ }^{16,30}$ In this study, there were no significant differences concerning time course of the infection. Fecal bacteria and coagulase-negative Staphylococci both caused mainly early infections. 
Gunne et al showed that $76 \%$ of all spinal infections were successfully treated after 1 revision surgery. ${ }^{22}$ In our study, the majority of infections were indeed treated after 1 revision $(60.9 \%)$, but we also found that fecal bacteria seem to be more difficult to treat than other bacteria. Only $38.9 \%$ of cases required 1 revision; in the other cases more surgical interventions were necessary.

PJIs of the hip and knee have been studied in depth and therapeutic guidelines concerning orthopedic implant-associated infections in general are frequently derived from these studies. ${ }^{11,15,16}$ Therefore, we were particularly interested in comparing the 2 entities in order to detect possible deviations which might be important concerning further treatment.

Compared with PJIs, we found 2 striking differences.

First, bacteria species detected in tissue samples differed significantly. In PJI, there were clearly more cases of infections caused by $S$. aureus and Streptococci spp. and significantly less caused by fecal bacteria.

Streptococci spp. infections have been described to occur typically late, presumably caused by hematogenous spread. ${ }^{31}$ Since most spinal infections occurred early on, it seems appropriate that there were hardly any streptococcal infections detected. However, why spinal implants seem to be protected from late infections caused by Streptococci spp. is not clear. Our data show that spinal infections occur mostly within the first 3 months, delayed and late infections were rare.

In PJIs on the other hand, only close to $30 \%$ of patients were affected early on and another one-third of infections occurred within 2 years. ${ }^{14}$ Patients with total joint replacement of the hip and knee were still at risk of developing implant-associated infections, even after 2 years $(34.7 \%)$ as opposed to the majority of patients with spinal implants.

In conclusion, we were able to show that surgical site infections following instrumented fixation of the spine are usually early infections caused predominantly by coagulasenegative Staphylococci and fecal bacteria. Around 60\% of these infections are resolved after 1 revision surgery, however, fecal bacteria seem to be more difficult to treat and they exhibit a more pronounced systemic inflammatory response (elevated CRP serum concentration). When deciding on an antibiotic prophylaxis or empiric antibiotic treatment in spinal implant-associated infections, not only Staphylococcus spp. should be addressed but also the possibility of an infection caused by fecal bacteria should be considered early on. Compared with PJIs, the risk of developing late implant-associated infections of the spine is rather low.

\section{Acknowledgments}

This study was funded by the University Hospital Heidelberg, Center for Orthopedics, Trauma Surgery and Spinal Cord Injury. Dr U Dapunt was supported by the Olympia-Morata-Scholarship of the Faculty of Medicine of Heidelberg University. The authors acknowledge the financial support of the Deutsche Forschungsgemeinschaft and Ruprecht-Karls-Universität Heidelberg within the funding programme Open Access Publishing.

\section{Disclosure}

The authors report no conflicts of interest in this work.

\section{References}

1. Poultsides LA, Liaropoulos LL, Malizos KN. The socioeconomic impact of musculoskeletal infections. J Bone Joint Surg Am. 2010; 92(11):e13.

2. Tsukayama DT. Pathophysiology of posttraumatic osteomyelitis. Clin Orthop Relat Res. 1999;(360):22-29.

3. Parsek MR, Singh PK. Bacterial biofilms: an emerging link to disease pathogenesis. Annu Rev Microbiol. 2003;57:677-701.

4. Costerton JW, Lewandowski Z, Caldwell DE, Korber DR, LappinScott HM. Microbial biofilms. Annu Rev Microbiol. 1995;49:711-745.

5. Stewart PS, Costerton JW. Antibiotic resistance of bacteria in biofilms. Lancet. 2001;358(9276):135-138.

6. Hoiby N, Bjarnsholt T, Givskov M, Molin S, Ciofu O. Antibiotic resistance of bacterial biofilms. Int J Antimicrob Agents. 2010;35(4): 322-332.

7. Costerton JW, Stewart PS, Greenberg EP. Bacterial biofilms: a common cause of persistent infections. Science. 1999;284(5418):1318-1322.

8. Arciola CR, An YH, Campoccia D, Donati ME, Montanaro L. Etiology of implant orthopedic infections: a survey on 1027 clinical isolates. Int J Artif Organs. 2005;28(11):1091-1100.

9. Montanaro L, Speziale P, Campoccia D, et al. Scenery of Staphylococcus implant infections in orthopedics. Future Microbiol. 2011;6(11): 1329-1349.

10. Nickinson RS, Board TN, Gambhir AK, Porter ML, Kay PR. The microbiology of the infected knee arthroplasty. Int Orthop. 2010;34(4): 505-510.

11. Tande AJ, Patel R. Prosthetic joint infection. Clin Microbiol Rev. 2014; 27(2):302-345

12. Stefansdottir A, Johansson D, Knutson K, Lidgren L, Robertsson O. Microbiology of the infected knee arthroplasty: report from the Swedish Knee Arthroplasty Register on 426 surgically revised cases. Scand J Infect Dis. 2009;41(11-12):831-840.

13. Woodford N, Livermore DM. Infections caused by Gram-positive bacteria: a review of the global challenge. $J$ Infect. 2009;59(Suppl 1): S4-S16.

14. Dapunt U, Stephanie R-M, Lehner B, Hänsch GM, Ewerbeck V. Bacterial infection and implant loosening in hip and knee arthroplasty: evaluation of 209 cases. Materials (Basel). 2016;9(11):871.

15. Zimmerli W. Clinical presentation and treatment of orthopedic implantassociated infection. J Intern Med. 2014;276(2):111-119.

16. Zimmerli W, Trampuz A, Ochsner PE. Prosthetic-joint infections. N Engl J Med. 2004;351(16):1645-1654.

17. Esposito S, Leone S. Prosthetic joint infections: microbiology, diagnosis, management and prevention. Int J Antimicrob Agents. 2008;32(4): 287-293.

18. Kim JI, Suh KT, Kim SJ, Lee JS. Implant removal for the management of infection after instrumented spinal fusion. J Spinal Disord Tech. 2010;23(4):258-265. 
19. Gerometta A, Rodriguez Olaverri JC, Bitan F. Infections in spinal instrumentation. Int Orthop. 2012;36(2):457-464.

20. Meredith DS, Kepler CK, Huang RC, Brause BD, Boachie-Adjei O. Postoperative infections of the lumbar spine: presentation and management. Int Orthop. 2012;36(2):439-444.

21. Mok JM, Guillaume TJ, Talu U, et al. Clinical outcome of deep wound infection after instrumented posterior spinal fusion: a matched cohort analysis. Spine (Phila Pa 1976). 2009;34(6):578-583.

22. Pull ter Gunne AF, Mohamed AS, Skolasky RL, van Laarhoven CJ, Cohen DB. The presentation, incidence, etiology, and treatment of surgical site infections after spinal surgery. Spine (Phila Pa 1976). 2010; 35(13):1323-1328.

23. Hegde V, Meredith DS, Kepler CK, Huang RC. Management of postoperative spinal infections. World J Orthop. 2012;3(11):182-189.

24. Eigner U, Holfelder M, Oberdorfer K, Betz-Wild U, Bertsch D, Fahr AM. Performance of a matrix-assisted laser desorption ionization-time-offlight mass spectrometry system for the identification of bacterial isolates in the clinical routine laboratory. Clin Lab. 2009;55(7-8):289-296.

25. Weinstein MA, McCabe JP, Cammisa FP Jr. Postoperative spinal wound infection: a review of 2,391 consecutive index procedures. $J$ Spinal Disord. 2000;13(5):422-426.
26. Fang A, Hu SS, Endres N, Bradford DS. Risk factors for infection after spinal surgery. Spine (Phila Pa 1976). 2005;30(12):1460-1465.

27. Cahill PJ, Warnick DE, Lee MJ, et al. Infection after spinal fusion for pediatric spinal deformity: thirty years of experience at a single institution. Spine (Phila Pa 1976). 2010;35(12):1211-1217.

28. Rechtine GR, Bono PL, Cahill DW, Bolesta MJ, Chrin AM. Postoperative wound infection after instrumentation of thoracic and lumbar fractures. J Orthop Trauma. 2001;15(8):566-569.

29. Mok JM, Pekmezci M, Piper SL, et al. Use of C-reactive protein after spinal surgery: comparison with erythrocyte sedimentation rate as predictor of early postoperative infectious complications. Spine (Phila Pa 1976). 2008;33(4):415-421.

30. El Helou OC, Berbari EF, Marculescu CE, et al. Outcome of enterococcal prosthetic joint infection: is combination systemic therapy superior to monotherapy? Clin Infect Dis. 2008;47(7):903-909.

31. Everts RJ, Chambers ST, Murdoch DR, Rothwell AG, McKie J. Successful antimicrobial therapy and implant retention for streptococcal infection of prosthetic joints. ANZ J Surg. 2004;74(4): $210-214$.
Therapeutics and Clinical Risk Management

\section{Publish your work in this journal}

Therapeutics and Clinical Risk Management is an international, peerreviewed journal of clinical therapeutics and risk management, focusing on concise rapid reporting of clinical studies in all therapeutic areas, outcomes, safety, and programs for the effective, safe, and sustained use of medicines. This journal is indexed on PubMed Central, CAS,

\section{Dovepress}

EMBase, Scopus and the Elsevier Bibliographic databases. The manuscript management system is completely online and includes a very quick and fair peer-review system, which is all easy to use. Visit http://www.dovepress.com/testimonials.php to read real quotes from published authors.

Submit your manuscript here: http://www.dovepress.com/therapeutics-and-clinical-risk-management-journal 